\title{
In vitro DNA protective potential of forskolin on hydroxyl and peroxyl radicals-induced DNA damage
}

Sanjt Matić1,*, Snežana Stanič2
Saniversity of Kragujevac, Institute for Information Technologies Kragujevac, Department of
Science, Jovana Cvijića bb, 34000 Kragujevac, Serbia
2University of Kragujevac, Faculty of Science, Department of Biology and Ecology, Radoja
Domanovića 12, 34000 Kragujevac, Serbia

\section{Introduction}

Forskolin (7 3 -Acetoxy-8,13-epoxy-1 $\alpha, 6 \beta, 9 \alpha$-trihydroxylabd-14-en-11one) is the labdane diterpenoid found only in the root of the plant Coleus forskohlii (Willd.) Briq. (Lamiaceae). This plant has been used in traditional medicine in the treatment of a various diseases such as heart, intestinal and respiratory disorders. Forskolin has been studied for its broad range of pharmacological properties such as anti-inflammatory, antimutagenic, antioxidant and anticarcinogenic activity. However forskolin has not been evaluated for DNA protective potential against hydroxyl and peroxyl radicals-induced DNA damage.

The present study was aimed to assess the in vitro DNA protective activity of forskolin in different concentrations $(25,50,100$, and 200 $\mu \mathrm{g} / \mathrm{ml}$ ) against hydroxyl radical-induced DNA damage with $\mathrm{Fe}^{2+}$ and $\mathrm{H}_{2} \mathrm{O}_{2}$ and peroxyl radical-induced DNA damage with 2,2'-azobis(2amidinopropane) dihydrochloride (AAPH).

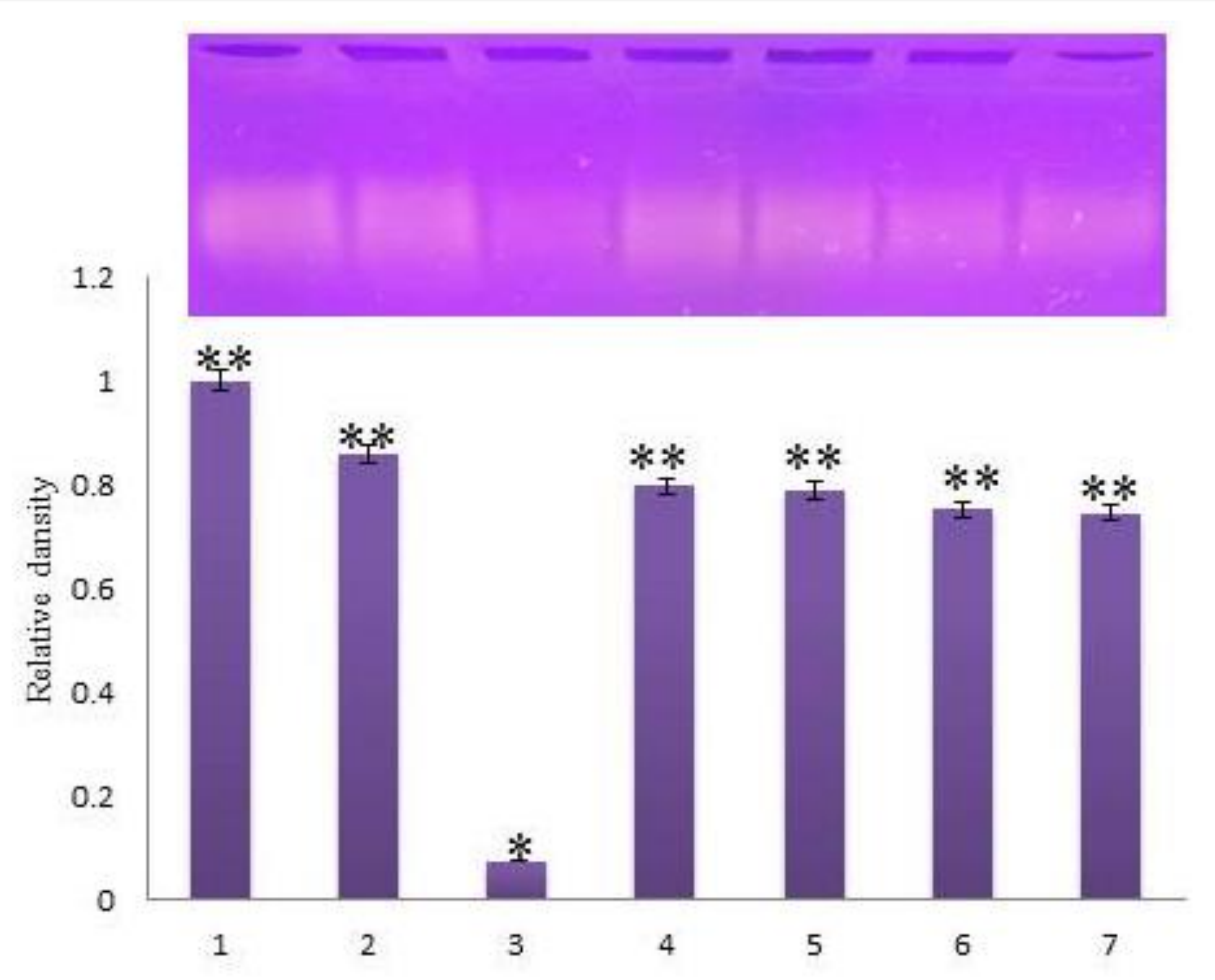

Figure 1. Agarose gel electrophoresis of hydroxyl radicals-induced DNA damage from herring sperm treated with different concentrations of forskolin. DNA from herring sperm (lane 1, negative control), quercetin (lane 2, $100 \mu \mathrm{g} / \mathrm{mL}$, standard), DNA damage induced by $\mathrm{FeSO}_{4}$ and $\mathrm{H}_{2} \mathrm{O}_{2}$ (lane 3, positive control), forskolin at the concentrations of $25,50,100$, and $200 \mu \mathrm{g} / \mathrm{mL}$ (lanes $4-7) . * p<0.05$ when compared with the negative control group; **p $<0.05$ when compared with the positive control group.
Materials and Methods

The protective activity of forskolin at various concentrations (25, 50,100 , and $200 \mu \mathrm{g} / \mathrm{mL}$ ) against hydroxyl radicals-induced DNA damage was assayed in vitro using DNA from herring sperm as a model system according to Lin et al. (2008) as previously described by Katanić et al. (2019). In this method, $\mathrm{FeSO}_{4}$ and $\mathrm{H}_{2} \mathrm{O}_{2}$ were used for the generation of hydroxyl radicals. The reference compound was the quercetin $(100 \mu \mathrm{M})$ (Poorna et al., 2013). The protective effect of forskolin against peroxyl radicals-induced DNA damage was assessed as previously described by Zhang et al. (2017). Oxidative damage of DNA was induced by (2methylpropionamidine) dihydrochloride (AAPH). The obtained DNA bands were visualized under UV light (UV transilluminator, Vilber Lourmat, France) at $365 \mathrm{~nm}$, photographed and recorded using ImageJ software (version 1.48 for Windows, Softonic International, Barcelona, Spain).

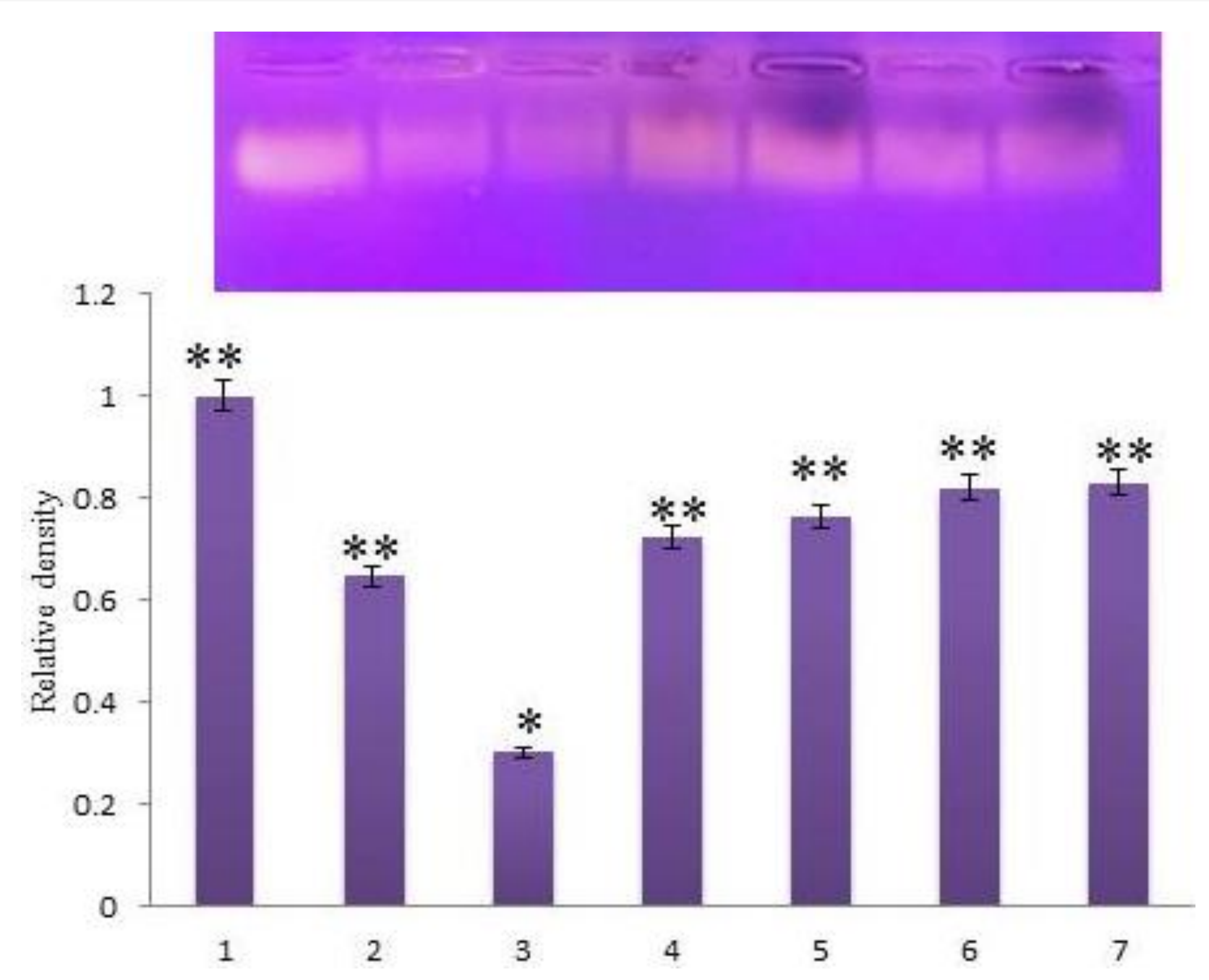

Figure 2. Agarose gel electrophoresis of peroxyl radicalsinduced DNA damage from herring sperm treated with different concentrations of forskolin. DNA from herring sperm (lane 1, negative control), quercetin (lane 2, $100 \mu \mathrm{g} / \mathrm{mL}$, standard), DNA damage induced by AAPH (lane 3, positive control), forskolin at the concentrations of $25,50,100$, and $200 \mu \mathrm{g} / \mathrm{mL}$ (lanes $4-7$ ). *p $<0.05$ when compared with the negative control group; **p $<0.05$ when compared with the positive control group.

\section{Results}

The results shown in Figure 1 indicate that forskolin possesses DNA-protective effects at all tested concentrations against hydroxyl radical-induced DNA damage with $\mathrm{Fe}^{2+}$ and $\mathrm{H}_{2} \mathrm{O}_{2}$. Also, high protection of forskolin on peroxyl radical-induced DNA damage were observed (Figure 2). Our data suggest that forskolin had the same ability to inhibit peroxyl- as well as hydroxyl radicals and possessed in vitro DNA-protective effect against hydroxyl- and peroxyl radicals induced DNA damage. In that sense, further research activities will be focused on DNA protective effects of forskolin by applying different assays and model organisms in in vivo condition.

\section{References}

Lin, Y.-W., Wang, Y. T., Chang, H.-M., \& Wu, J. S.-B. (2008). DNA protection and antitumor effect of water extract from residue of jelly fig (Ficus awkeotsang Makino) achenes. Journal of Food and Drug Analysis, 16, 63-69.

Katanić J, Yousfi F, Caruso MC, Matić S, Monti DM, Loukili EH, Boroja T, Mihailović V, Galgano F, Imbimbo P, Petruke G, Bouhrim M, Bnouham M, Ramdani M. Characterization of bioactivity and phytochemical composition with toxicity studies of different Opuntia dillenii extracts from Morocco, Food Bioscience, 2019, 30, 100410

Poorna, C.A., Resmi, M., Soniya, E., 2013. In vitro antioxidant analysis and the DNA damage protective activity of Leaf extract of the Excoecaria agallocha Linn Mangrove plant, Agricultural Chemistry. InTech 1-4. Zhang LL, Zhang LF, Xu JG, Hu QP (2017) Comparison study on antioxidant, DNA damage protective and antibacterial activities of eugenol and isoeugenol against several foodborne pathogens, Food and Nutrition Research, 61:1, 1353356, DOI: 10.1080/16546628.2017.1353356 